\title{
The influence of different storage temperature on changes of Delphinidin-3-0-glucoside and Malvidin-3-O-glucoside
}

\author{
Yuan $\mathrm{Li}^{1{ }^{1,},}$, Yuxin Wang ${ }^{1}$, Maolan Yue ${ }^{1}$, Ya Luo ${ }^{1, *}$ and Xun Wang ${ }^{2, a}$ \\ ${ }^{1}$ College of Horticulture, Sichuan Agricultural University, Chengdu, Sichuan, China \\ ${ }^{2}$ Institute of Pomology \& Olericulture, Sichuan Agricultural University, Chengdu, Sichuan, China \\ a wangxun0104@hotmail.com \\ *The first author
}

\begin{abstract}
Keywords: Blueberry; anthocyanin; storage temperature.
Abstract. Blueberry is known as the highest anthocyanin fruit in the world. Blueberry matures between June and August, which is the hottest and wettest time, fruit quality tends to drop. In this experiment, the changes of Delphinidin-3-O-glucoside (Del-glc) and Malvidin-3-O-glucoside (Mal-glc) in different maturity fruits (purple fruit and ripe fruit) and storage temperatures $\left(4^{\circ} \mathrm{C}\right.$ and $\left.25^{\circ} \mathrm{C}\right)$ were measured for a week. We found that in the same storage temperature, both anthocyanin contents in the ripe fruit were higher than that in the purple fruit. The average of both anthocyanins contents were going for an up-down-up mode, and the final value was higher than the initial value. Different anthocyanins in different maturity fruits and storage temperatures showed in different tendencies.
\end{abstract}

\section{Introduction}

Blueberry (Vaccinium spp.), also known as huckleberry, is a perennial deciduous or evergreen shrub. Blueberry is rich in anthocyanin, which can improve vision, reduce dazzle, improve night vision, and improve dark adaptation ability ${ }^{[1-3]}$. The world health organization considers blueberry to be one of the most antioxidative fruit and is recommended by the FAO as one of the five healthy fruits ${ }^{[4]}$.

Although blueberries have a variety of processed products, but now, consumer is more likely to eat blueberry in fresh. Blueberry matures between June and August, which the temperature and humidity are highest, fruit postharvest easily become angry decay, seriously affect the economic value of blueberry.

Anthocyanins are anthocyanidins' glycosidic and acyl indican derivatives, their chemical property are active, not stable, easy to degradation during processing and storage, and cause food color change and quality of food decline ${ }^{[5]}$. The changes of individual anthocyanins in different storage temperatures were measured and their dynamic changes were investigated to provide theoretical basis for predicting the change mechanism of the shelf life and anthocyanins of blueberry fruits.

\section{Materials and methods}

Plant material and postharvest treatments. Pick 'Brigitta' blueberry's purple fruit and ripe fruit, storage half of them at a refrigerator for $4^{\circ} \mathrm{C}$, the rest are at an incubator for $25^{\circ} \mathrm{C}$. Measure the content of Delphinidin-3-O-glucoside (Del-glc) and Malvidin-3-O-glucoside (Mal-glc) in purple fruit and ripe fruit in the 1,3,5 and 7 days after storage.

Anthocyanin extraction methods. $1 \mathrm{~g}$ sample was taken. After grinding, $5 \mathrm{~mL} 1 \%$ hydrochloric acid- methanol leaching solution was added, and extracted at $4{ }^{\circ} \mathrm{C}$ by avoiding light overnight. Centrifuged them in the second day at $4^{\circ} \mathrm{C}, 6500 \mathrm{r} \cdot \mathrm{min}^{-1}$ for $15 \mathrm{~min}$, took the supernatant, filtered with $0.22 \mu \mathrm{m}$ organic filter membrane and then test.

Anthocyanin measurement methods. The content of anthocyanin was determined by Agilent 1260 liquid chromatograph, the flow phase A was ultrapure water, the flow phase B was acetonitrile (HPLC grade), and the flow phase $\mathrm{C}$ was formic acid (HPLC grade). Gradient elution program were shown in table 1.20 minutes with a flow rate of $0.5 \mathrm{~mL} \cdot \mathrm{min}^{-1}$ and the column temperature set to $25^{\circ} \mathrm{C}$. Injection volumes were $10 \mu \mathrm{L}$. Anthocyanin were detected by their absorbance at $525 \mathrm{~nm}$. 
Table 1 Gradient elution program of HPLC

\begin{tabular}{cccc}
\hline Time $[\mathrm{min}]$ & $\mathrm{A}[\%]$ & $\mathrm{B}[\%]$ & $\mathrm{C}[\%]$ \\
\hline 0 & 90 & 8.4 & 1.6 \\
4 & 90 & 8.4 & 1.6 \\
13 & 75 & 23.4 & 1.6 \\
20 & 60 & 38.4 & 1.6
\end{tabular}

Standard curve measurement methods. External standard method of quantitative analysis of a single content of anthocyanin, according to a certain amount of standard substance, respectively dissolved in methanol, configuration into a single standard, diluted to different concentrations of methanol $\left(0.5 \mu \mathrm{g} \cdot \mathrm{mL}^{-1}, 1 \mu \mathrm{g} \cdot \mathrm{mL}^{-1}, 2 \mu \mathrm{g} \cdot \mathrm{mL}^{-1}, 4 \mu \mathrm{g} \cdot \mathrm{mL}^{-1}, 8 \mu \mathrm{g} \cdot \mathrm{mL}^{-1}, 10 \mu \mathrm{g} \cdot \mathrm{mL}^{-1}\right)$ for HPLC analysis.

Statistical analysis. Excel 2010 was used to conduct data statistics and draw charts, SPSS 19.0 software was used for data analysis. The anthocyanin content was measured in triplicate and data represent mean values \pm standard deviation.

\section{Results}

The content of Delphinidin-3-O-glucoside (Del-glc) in different storage temperatures changed as figure 1. Del-glc in the purple fruit at $4{ }^{\circ} \mathrm{C}$ for seven days, its content was going to an up-down mode, reached the maximum of $1.53 \mu \mathrm{g} / \mathrm{mL}$ on the third day, and on the seventh day, the minimum was 1.07 $\mu \mathrm{g} / \mathrm{mL}$. Del-glc in the purple fruit at $25^{\circ} \mathrm{C}$ for seven days, its content was also going to an up-down mode, reached the maximum of $1.37 \mu \mathrm{g} / \mathrm{mL}$ on the third day and on the first day, the minimum was $0.87 \mu \mathrm{g} / \mathrm{mL}$. While in the ripe fruit at $4^{\circ} \mathrm{C}$ for seven days, Del-glc's content was going to an down-up mode, on the first day, the maximum was $1.54 \mu \mathrm{g} / \mathrm{mL}$ and on the fifth day, the minimum was 1.01 $\mu \mathrm{g} / \mathrm{mL}$. In the ripe fruit at $25^{\circ} \mathrm{C}$ for seven days, Del-glc's content was also going to a down-up mode, got the maximum of $1.60 \mu \mathrm{g} / \mathrm{mL}$ on the seventh day and the minimum was $1.37 \mu \mathrm{g} / \mathrm{mL}$ on the third day.

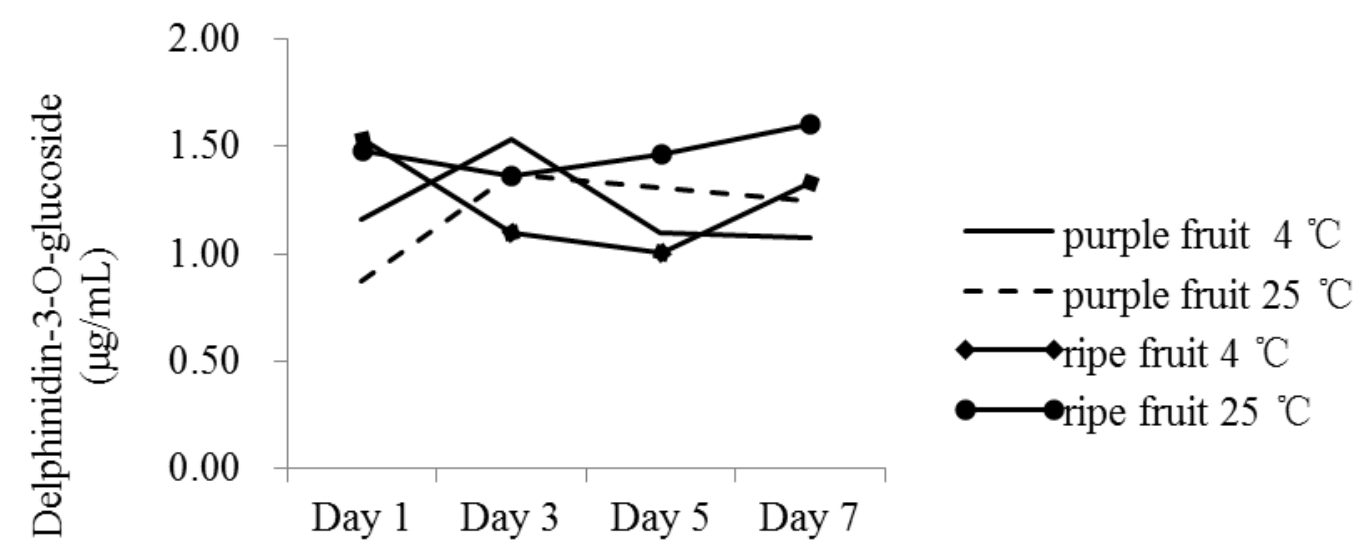

Storage days

Fig. 1 Changes in Delphinidin-3-O-glucoside in different storage temperatures.

The content of Malvidin-3-O-glucoside (Mal-glc) in different storage temperatures changed as figure 2. Blueberry was stored in the purple fruit at $4{ }^{\circ} \mathrm{C}$ for seven days, the content of Mal-glc generally showed the trend of first rise and then decrease, reached the maximum of $1.42 \mu \mathrm{g} / \mathrm{mL}$ on the third day, reached the minimum of $0.54 \mu \mathrm{g} / \mathrm{mL}$ on the fifth day. Stored in the purple fruit at $25^{\circ} \mathrm{C}$ for the same days, the content of Mal-glc generally showed the trend of rise. It reached the maximum of $1.81 \mu \mathrm{g} / \mathrm{mL}$ on the seventh day, and reached the minimum of $0.49 \mu \mathrm{g} / \mathrm{mL}$ on the first day. Stored in the ripe fruit at $4^{\circ} \mathrm{C}$ for seven days, the content of Mal-glc was going for a down-up mode, reached the maximum of $1.44 \mu \mathrm{g} / \mathrm{mL}$ on the seventh day and the minimum of $1.08 \mu \mathrm{g} / \mathrm{mL}$ on the third day. Stored 
in the ripe fruit at $25^{\circ} \mathrm{C}$ for the same days, the content of Mal-glc showed the trend of rise, reached the maximum of $2.53 \mu \mathrm{g} / \mathrm{mL}$ on the seventh day and the minimum of $2.12 \mu \mathrm{g} / \mathrm{mL}$ on the first day.

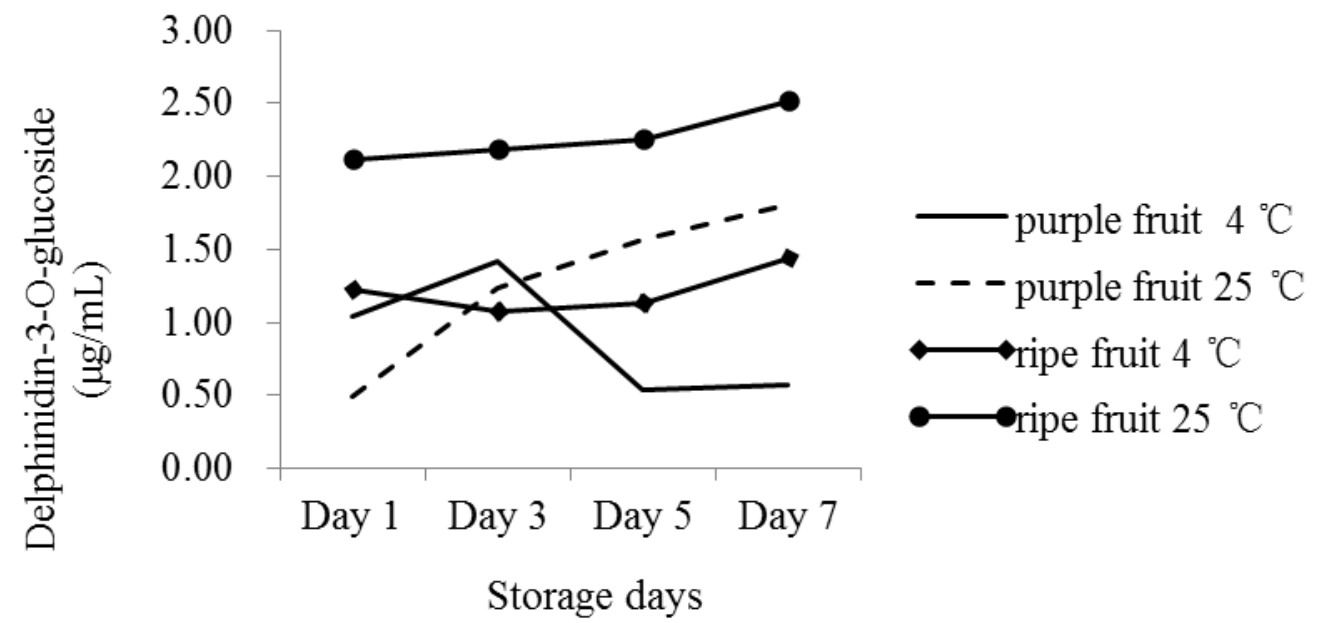

Fig.2 Changes in Malvidin-3-O-glucoside in different storage temperatures.

In the same storage temperature, both anthocyanin contents in the ripe fruit are higher than which are in the purple fruit. The average of both anthocyanin contents are going for an up-down-up mode, and the final value is higher than the initial value.

\section{Conclusions}

There have been some previous studies on the blueberry storage test, and they found that: the thermal stability of the anthocyanins in blueberry juice was poor, and the higher of the heating temperature, the faster the degradation of anthocyanin. The addition of ascorbic acid can reduce the thermal stability of anthocyanin in blueberry juice, accelerate the heating degradation of blueberry anthocyanin, and the higher the concentration, the greater the influence ${ }^{[6]}$. the color of blueberry juice is better preserved at $4^{\circ} \mathrm{C}$, and it changed greatly at $25^{\circ} \mathrm{C}$ and $27^{\circ} \mathrm{C}$. The total anthocyanin and individual anthocyanin were decreased during storage ${ }^{[7]}$. Wild blueberry powder maintained at $25^{\circ} \mathrm{C}$, $42^{\circ} \mathrm{C}, 60^{\circ} \mathrm{C}$, and $80^{\circ} \mathrm{C}$ for 49 days, storage reduced single and total anthocyanin content at all of the temperatures ${ }^{[8]}$. The degradation of anthocyanin at each temperature level followed a first-order kinetic model, and the values of half-life time at temperatures of 40, 50, 60, 70, and 80 degrees were found to be $180.5,42.3,25.3,8.6$, and $5.1 \mathrm{~h}$, respectively. The activation energy value of the degradation of the 8.9 degrees Brix blueberry juice during heating was $80.4 \mathrm{~kJ} / \mathrm{mol}^{[9]}$.

\section{References}

[1] X.D. Cao, X.G. Fang and S.Y. Li: Chinese Agricultural Science Bulletin Vol. 28(2012), p. 221-226

[2] X.L. Zhao: Chinese Wild Plant Resources Vol. 30(2011), p. 19-23

[3] H.G. Yan, W.H. Zhang and Z.E. Ding: Science and Technology of Food Industry Vol. 34(2013), p. $119-124$

[4] P.X. Han, B. Zhang, S.Q. Feng: Science and Technology of Food Industry Vol. 36(2015), p. 370-379

[5] A. Patras, N.P. Brunton, C. O’Donnell and B.K. Tiwari: Trends In Food Science \& Technology Vol. 21(2010), p. 3-11

[6] X.D. Cao, X.G. Fang, K. Zhao, Z.L. Yao and F.F. Li: Journal of Chinese Institute of Food Science and Technology Vol. 13(2013), p. 47-57 
[7] B. Zou, Y.J. Xu, J.J. Wu, M.Q. Fu, G.S. Xiao and S.W. Lu: Modern Food Science and Technology Vol. 31(2013), p. 256-276

[8] D. Fracassetti, B.C. Del, P. Simonetti, C. Gardana, D. Klimis-Zacas and S. Ciappellano: Journal of Agricultural \& Food Chemistry Vol. 61(2013), p. 2999-3005

[9] C.P. Kechinski, P.V. Guimarães , C.P. Noreña , I.C. Tessaro and L.D. Marczak: Journal of Food Science Vol. 75(2010), p. C173-C176 